\title{
Cloning, Purification, and Characterization of a Novel Metagenome-Sourced Microbial Chitinase with Dual Catalytic Domains
}

\section{Yumei Dai ( $\nabla$ daiym@cib.ac.cn )}

Chengdu Institute of Biology, Chinese Academy of Sciences https://orcid.org/0000-0002-0601-1806

\section{Feng Yang}

Chengdu institute of Biology, Chinese Academy of Sciences

Xiao Liu

Chengdu Institute of Biology, Chinese Academy of Sciences

\section{Hongling Wang}

Chengdu institute of Biology, Chinese Academy of Sciences

\section{Zhiying Yan}

Chengdu Institute of Biology, Chinese Academy of Sciences

\section{Research}

Keywords: chitinases, dual GH18 domains, metagenomic approach, cold-adapted, synergy

Posted Date: June 30th, 2020

DOl: https://doi.org/10.21203/rs.3.rs-38123/v1

License: (9) This work is licensed under a Creative Commons Attribution 4.0 International License. Read Full License 
Cloning, purification, and characterization of a novel metagenome-sourced microbial chitinase with dual catalytic domains

\section{Affiliation:}

${ }^{1}$ Key Laboratory of Environmental and Applied Microbiology, Environmental Microbiology Key Laboratory of Sichuan Province, Chengdu Institute of Biology,

Chinese Academy of Sciences, Sichuan 610041, People's Republic of China ${ }^{2}$ University of Chinese Academy of Sciences, Beijing, 100049, P.R. China

Running title: A novel chitinase with dual catalytic domains

\section{*Author for corresponding:}

Yumei Dai, Email: daiym@ cib.ac.cn

Zhiying Yan, Email: yanzy@cib.ac.cn

Address: Chengdu Institute of Biology, Chinese Academy of Sciences

No.9, Section 4, Renmin Nan Road, 610041, Chengdu, China 


\section{Abstract}

42 Background: Microbial chitinases have attracted a lot of attention because of their great potential in many applications. Metagenome-based approach obtains the target genes from the environment directly without culturing the microbes and is becoming a powerful tool to discover the novel chitinases.

Results: A metagenomic approach was used to discover the chitinases from a wetland on the Qinghai-Tibetan plateau. Gene P1724 was found and predicted to have two GH18 catalytic domains. Gene sequence containing P1724, only its N-terminal GH18 domain (P1724nGH18) or only C-terminal GH18 domain (P1724cGH18) were cloned and expressed in Escherichia coli BL21 (DE3). These purified recombinant chitinases showed maximum hydrolytic activities at $40^{\circ} \mathrm{C}$, $\mathrm{pH}$ 5.0-6.0 and 0-0.5 $\mathrm{M} \mathrm{NaCl}$, and were cold adaptive since they were still active at $4{ }^{\circ} \mathrm{C}$. The activities of three chitinases were decreased with the presence of $\mathrm{Cu}^{2+}$ and EDTA, but increased with $\mathrm{Ba}^{2+}$ and $\mathrm{Ca}^{3+}$. All three chitinases showed both chitotiosidase and endochitinase activities, and produced predominantly $\mathrm{N}, \mathrm{N}^{\prime}$-Diacetylchitobiose from colloid chitin. Other than these common characteristics, $\mathrm{P} 1724$ and $\mathrm{P} 1724 \mathrm{nGH} 18$ shared more similarity in temperature and $\mathrm{pH}$ stabilities, $\mathrm{NaCl}$ tolerance and substrate affinity, suggesting the $\mathrm{N}$-terminal GH18 domain contributed more than the C-terminal GH18 did in biochemical characteristics of P1724. $k_{c a t} / K_{m}$ value (catalytic efficiency) of P1724 was significantly higher than the sum values of P1724nGH18 and P1724cGH18's, which indicated that two GH18 domains of P1724 works synergistically in degrading chitin.

Conclusion: Compared to the most of microbial chitinases containing only one catalytic domain, chitinases P1724 with two GH18 catalytic domains was discovered firstly by the metagenomic approach. P1724 is a novel chitinase with unique amino acid sequences and hydrolytic mode, and could be used in cold environments or industries. 
66 Keywords: chitinases, dual GH18 domains, metagenomic approach, cold-adapted,

67 synergy.

\section{Background}

69 Chitin is the second most abundant natural polymer, behind only cellulose, and a major 70 component of fungal cell walls, the exoskeleton and gut lining of insects, and the shells

71 of crustaceans [1]. Enzymes are biological catalysts that could speed up biochemical reactions with specificity, speed, and efficiency [2], and chitinases are ones of these enzymes and catalyze the degradation of chitin . Chitinases have shown the great application potential in the biocontrol of plant pathogenic fungi, synthesis of chitooligosaccharides for the food and pharmaceutical industry, treatment of marine wastes and production of biofuels etc. [1,3]; therefore, many studies have tried to discover novel chitinases with better properties $[4,5]$. chitinolytic microorganisms first, and then obtaining their (heterologously) expressed

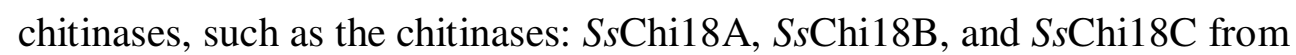
Streptomyces sp. F-3 [6], CmChi1 from Chitinolyticbacter meiyuanensis SYBC-H1 [7], MtCh509 from Microbulbifer thermotolerans DAU221 [8] , PbChi74 from Paenibacillus barengoltzii [9], etc. However, it is well known that the vast majority (up to $99-99.9 \%$ ) of microorganisms present in nature, especially those in the extreme environments, cannot be cultured under laboratory conditions, which is one of the biggest obstacles to discover the novel enzymes/chitinases [10]. Metagenome-based approaches are the complete access to the entire community's genetic pool without the need of microbial cultivation [11], which have been used to discover a few chitinases [12]. These metagenome-sourced chitinases could be used for the biocontrol of pathogenetic fungi [13] and insects [12, 14], an additive in the food and feed industries 
91 [15], as well as industrial processing of chitin [16].

92 Based on amino acid sequence similarity, chitinases are grouped into glycosyl hydrolase

$93(\mathrm{GH})$ families 18, 19, and 20 [1]. Bacterial chitinases mainly belong to GH18, some

94 Streptomyces chitinases are GH19, and GH20 includes the $\beta$-N-acetylhexosaminidases

95 from bacteria [1]. GH18 chitinases usually contain one catalytic GH18 domain and

96 several auxiliary domains [5], while four microbial chitinases with dual GH18 catalytic

97 domains have been reported so far [17-20]. These chitinases with dual GH18 domains

98 had shown the advantages over the ones with a single catalytic domain due to: 1) the

99 two GH18 domains in combination exhibited a significantly higher activity than the sum

100 of their individual activities and/or 2) the two domains contributed different catalytic

101 modes [15]. For examples, in the chitinase Tk-ChiA from T. kodakaraensis KOD1 and

102 the chitinase B from "Microbulbifer degradans" 2-40 (now Saccharophagus degradans

$1032-40$ [21]), the N-terminal and C-terminal GH18 domains functioned as an exo-chitinase

104 and an endo-chitinase respectively $[18,19]$.

105 Here we reported the first metagenome-sourced chitinase that contained two GH18

106 catalytic domains. In our previous study, we found the microbial communities from the

107 Qinghai-Tibetan Plateau wetland soils could effectively convert chitin to methane at

108 low temperatures [22]. We continued to anaerobically enrich the microbial community

109 from Haiyan wetland soil with chitin flakes as a sole carbon resource, and then

110 next-generation metagenomic sequencing was done on the community. Gene P1724

111 predicted to have two GH18 catalytic domains was discovered, and then cloned,

112 expressed, purified, and characterized. In addition, two GH18 domains of P1724 were

113 individually cloned, expressed, purified, and characterized in E. coli. The results

114 showed the P1724 is a novel chitinase with two GH18 domains working synergistically

115 and could be used in cold environments or industries. 


\section{Discovery and sequence analysis of P1724}

118 A chitin-enriched microbial community was obtained from the Haiyan wetland soil on 119 the Qinghai-Tibetan plateau after two-years of repeated subculturing. Next-generation metagenomic sequencing and CAZyme annotation revealed that the metagenome of the chitin-enriched microbial community encoded a broad array of potential enzymes (details were shown here). Gene P1724 (2880 bp) was found and encoded a protein (960 amino acids) containing GH18 domains (the details of the sequences can be seen in the additional file). Based on the InterPro search, P1724 was composed of four domains, two GH18 domains and two carbohydrate-binding modules of family 5/12 (CBM 5/12) (Fig.1). Most likely P1724 does not contain secretion signal since a sec signal peptide was predicted by using the SignalP-5.0 server with only 0.4283 of the likelihood. However, the InterPro search showed the P1724 was in the extracellular region, which corresponded to the fact that chitinases were often secreted enzymes. The amino acid sequence of $\mathrm{P} 1724$ was compared with the sequences in non-redundant protein sequences database (nr) in GenBank, and had the best BLAST hit (95\% query cover and $60.10 \%$ identity) with a hypothetical protein from Clostridium sp. Marseille-P299 of two distinct catalytic domains, but have not been further studied. Based on the unique primary structure and similarity analysis, we concluded that P1724 was a novel chitinase.

140 The two catalytic domains of P1724 located from residues 28 to 397 and 669 to 941 of 
141 P1724 respectively (Fig. 1). BLAST analysis revealed that the amino acid sequence of the N-terminal and C-terminal GH18 domains (nGH18 and cGH18) were only $24.4 \%$ identical and phylogenetically distanced to each other (Fig. 2). Figure 2 also showed10 sequences that had the highest identities (79.9-49.4\%) with nGH18 or cGH18 in nr database; these sequences have not been characterized so far and belonged to Clostridium sp. Marseille-P299, Lachnoclostridium spp., Anaerocolumna spp., Ruminiclostridium spp. etc. For the nGH18, the InterPro search also showed it contained a Chitinases Insertion Domain (CID) from residues 292 to 368, while cGH18 had no such domain (Fig.1). The BLAST search in UniProtKB/Swiss-Prot database showed that nGH18 had the best hit (43.1\%) with the domain of Chitinase A1 of Bacillus circulans, while cGH18 had the best hit (35.90\%) with Chitinase D of $B$. circulans. Chitinase A1 and Chitinase D belong to chitinase subfamily A and B respectively [23], and so $\mathrm{nGH} 18$ and cG18 should belong to different subfamilies as well.

\section{Cloning, expression, and purification of recombinant P1724 and its individual}

\section{GH18 domain}

Three fragments (Fig.1), P1724 (nt 31-2880), P1724nGH18 containing nGH18 (nt 31 to 1884) and P1724cGH18 containing cGH18 (nt 1372 to 2880) were amplified by PCR and then cloned into the pCold I respectively. The first 10 amino acids were eliminated to avoid their potential effect on the solubility of recombinant protein. All fragments

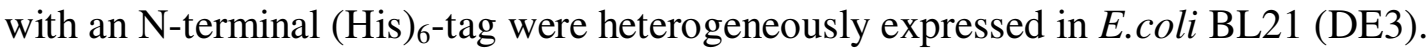
The constructions of $P 1724 n G H 18$ and $P 1724 c G H 18$ were made to investigate how these two GH18 domains function individually. If the position of CMBs, at the middle, $\mathrm{N}$-terminal or C-terminal position of proteins, would not affect the catalytic abilities, (Fig. 1), the only difference between the three recombinant proteins would only rely on 
their catalytic domain(s). Figure 3 a showed the molecular weight analysis of three purified recombinant proteins, and their molecule weight mostly corresponded to their theoretical molecular mass 102.9, 67.5, and 53.9 kDa calculated by ProtParam Tool [24].

The Native PAGE and zymogram showed there were clear zones around three purified protein bands (Fig. 3b, 3c).

\section{Effects of temperature on the activities of P1724 and its individual GH18 domains}

To estimate their optimum hydrolytic temperatures, all three purified recombinant chitinases were incubated at $4-60{ }^{\circ} \mathrm{C}$ for $1 \mathrm{~h}$ using colloid chitin as the substrate. The results showed that $\mathrm{P} 1724, \mathrm{P} 1724 \mathrm{nGH} 18$, and P1724cGH18 achieved maximum activities around $40{ }^{\circ} \mathrm{C}$ (Fig. 4a). The maximum activities were set to $100 \%$ then. Fig. 4a showed that three chitinases were still active at low temperatures, for example, three chitinases kept $16-35 \%$ of their maximal activities at $4{ }^{\circ} \mathrm{C}$; at $45-50^{\circ} \mathrm{C}, \mathrm{P} 1724 \mathrm{cGH} 18$ still kept $100 \%$ of its maximal activity, while the activities of P1724 and P1724nGH18 dropped significantly. For the estimation of temperature stabilities, the recombinant chitinases were preincubated at $4-60{ }^{\circ} \mathrm{C}$ without the substrate for an hour, and then assayed for their residual hydrolytic activities at $40{ }^{\circ} \mathrm{C}$. The activities of three chitinases preincubated at $4{ }^{\circ} \mathrm{C}$ were set to $100 \%$. Figure $4 \mathrm{~b}$ showed all three chitinases were stable at $4-40{ }^{\circ} \mathrm{C}$ and kept $\sim 100 \%$ activities. Preincubated at $45{ }^{\circ} \mathrm{C}, \mathrm{P} 1724$ and P1724nGH18 almost lost all of their hydrolytic activities, while P1724cGH18 still kept $100 \%$ of its. Overall, compared to P1724 and P1724nGH18, P1724cGH18 was more active and stable at higher temperatures.

Effects of pH on the activities of P1724 and its individual GH18 domains The effects of $\mathrm{pHs}$ on the recombinant chitinases were determined at $\mathrm{pH} 3.0-10.0$ buffer systems. Chitinase P1724, P1724nGH18, and P1724cGH18 exhibited maximum activities around pH 5.0-6.0 (Fig. 4c). The maximum activities of three chitinases were 
set to $100 \%$. Figure $4 \mathrm{c}$ showed that their activities dropped significantly (> 50\%) when at the $\mathrm{pH} \leq 3.0$ and $\mathrm{pH} \geq 7.0$. For estimating the $\mathrm{pH}$ stabilities, the recombinant chitinases were kept in $\mathrm{pH} 3.0-10.0$ buffers at $4{ }^{\circ} \mathrm{C}$ for $24 \mathrm{~h}$, and then assayed for their residual hydrolytic activities at $\mathrm{pH} 6$ and $40{ }^{\circ} \mathrm{C}$. All three chitinases were stable and showed the highest activities after preincubated for $24 \mathrm{~h}$ at $\mathrm{pH} 5.0$ and 6.0, and then these highest activities were set to $100 \%$ (Fig. 4d). When at neutral and alkaline conditions ( $\mathrm{pH}$ 7.0-10.0), all recombinant chitinases could keep relatively high activities (> 50\%) (Fig. 4d). When preincubated at $\mathrm{pH} 3.0$ and 4.0, P1724 and P1724nCH18 lost more than $80 \%$ of their maximum activities, while P1724nCH18 was not affected at all and kept $100 \%$ of its maximum activity (Fig. 4d). Overall, compared to P1724 and P1724nGH18, P1724cGH18 could adapt wider $\mathrm{pH}$ range.

\section{Effects of $\mathrm{NaCl}$ and metal ions on the activities of P1724 and its individual GH18}

\section{domains}

The effects of $\mathrm{NaCl}$ on the recombinant chitinases were tested in the reaction mixtures with the final concentrations of $0-3 \mathrm{M}$ of $\mathrm{NaCl}$. The activities of three chitinases were set to $100 \%$ at $0 \mathrm{M} \mathrm{NaCl}$. All three chitinases kept about $100 \%$ activities at $0.5 \mathrm{M} \mathrm{NaCl}$, but decreased linearly at higher concentrations of $\mathrm{NaCl}$ (Fig. 5). P1724 and P1724nGH18 lost 50\% their activities around $1.25 \mathrm{M} \mathrm{NaCl}$, while P1724cGH18 lost about $50 \%$ when around $1.75 \mathrm{M} \mathrm{NaCl}$. The effects of metal irons were estimated in the reaction mixtures with $1 \mathrm{mM}$ or $5 \mathrm{mM}$ of the metal irons. These irons were $\mathrm{Ba}^{2+}, \mathrm{Ca}^{2+}$, $\mathrm{Co}^{2+}, \mathrm{Cu}^{2+}, \mathrm{Fe}^{3+}, \mathrm{K}^{+}, \mathrm{Li}^{+}, \mathrm{Mg}^{2+}, \mathrm{Mn}^{2+}, \mathrm{Zn}^{2+}$, as well as EDTA and dithiothreitol (DTT). The activities of three recombinant chitinases were set to $100 \%$ at the concentration of 0 M of the compounds. For P1724, its activities were increased (>100\%) when most of the irons presented in the reaction, but were obviously decreased $(<100 \%)$ when $\mathrm{Cu}^{2+}$, $\mathrm{Fe}^{3+}$, and EDTA presented (Fig. 6a). The activities of $1724 \mathrm{nGH} 18$ decreased with the 
216 presence of $\mathrm{Cu}^{2+,} \mathrm{Co}^{2+}, \mathrm{Fe}^{3+}, \mathrm{Mg}^{2+}$, and EDTA, but increased with $\mathrm{Ba}^{2+}$ and $\mathrm{Ca}^{3+}$ (Fig.

217 6b). For P1724cGH19, its activities obviously increased with the presence of $\mathrm{Ba}^{2+}, \mathrm{Ca}^{2+}$,

$218 \mathrm{Fe}^{3+}, \mathrm{Li}^{+}$, and DTT, and decreased when $\mathrm{Cu}^{2+}, \mathrm{Co}^{2+}$, and EDTA presented (Fig. 6c). In

219 general, $\mathrm{Cu}^{2+}$ and EDTA had negative effects on the P1724 and its individual domains,

220 and $\mathrm{Ba}^{2+}$ and $\mathrm{Ca}^{3+}$ had positive effects on them; $\mathrm{Fe}^{3+}$ had negative effects on $\mathrm{P} 1724$ and

221 its nGH18 domain, but showed a positive effect on the cGH18 domain.

Substrate specificity of P1724 and its individual GH18 domains

Other than colloid chitin, the recombinant chitinases were also tested to see if they

could hydrolyze on other polysaccharides as indicated in Table 1 . When the colloid chitin was used as the substrate, P1724 had the highest specific activity, followed by P1724nGH18, and then P1724cGH18; the specific activity of P1724 is about $0.3 \mathrm{U} / \mathrm{mg}$ higher than the sum of P1724nGH18 and P1724cGH18 (Table 1). All three chitinases showed much higher hydrolytic activities towards the fluorimetric 4-Methylumbelliferyl (MU)- $\beta$-D-N, $\mathrm{N}^{\prime}$-diacetylchitobioside hydrate and 4-MU- $\beta-\mathrm{D}-\mathrm{N}, \mathrm{N}^{\prime}, \mathrm{N}^{\prime \prime}$ -triacetylchitotriose than other tested polysaccharides, and no obvious hydrolytic activity on 4-MU N-acetyl- $\beta$-D-glucosaminide (Table 1); in another word, all three chitinases had chitobiosidase and endochitinase activities, and no $\beta$-N-acetylglucosaminidase activity; In addition, all three chitinases showed different cellulose (Table 1). 


\begin{tabular}{llll}
\hline Substrates & P1724 & P1724nGH18 & P1724cGH18 \\
& $(\mathrm{U} / \mathrm{mg})$ & $(\mathrm{U} / \mathrm{mg})$ & $(\mathrm{U} / \mathrm{mg})$ \\
\hline colloid chitin & $2.9 \pm 0.2$ & $1.5 \pm 0.1$ & $1.1 \pm 0.1$ \\
4-MU N-acetyl- $\beta$-D-glucosaminide & $\mathrm{ND} *$ & $\mathrm{ND}$ & $\mathrm{ND}$ \\
4-MU- $\beta$-D-N, $\mathrm{N}^{\prime}$-diacetylchitobioside & $1076.2 \pm 8.0$ & $396.4 \pm 20.2$ & $729.2 \pm 75.5$ \\
4-MU- $\beta$-D-N, $\mathrm{N}^{\prime}, \mathrm{N}^{\prime \prime}$-triacetylchitotriose & $1198.2 \pm 26.2$ & $783.5 \pm 38.3$ & $225.2 \pm 19.7$ \\
Chitin powder $(10 \%)$ at $40^{\circ} \mathrm{C} / 4^{\circ} \mathrm{C}$ & $0.15 / 0.03$ & $0.06 / 0.02$ & $0.03 / 0.02$ \\
Chitin powder (1\%) & $\mathrm{ND}$ & $\mathrm{ND}$ & $\mathrm{ND}$ \\
Colloid chitosan (DS $\geq 90 \%)$ & 0.09 & 0.09 & 0.06 \\
Chitosan powder (DS $\geq 90 \%)$ & $\mathrm{ND}$ & $\mathrm{ND}$ & $\mathrm{ND}$ \\
CMC & $\mathrm{ND}$ & $\mathrm{ND}$ & $\mathrm{ND}$ \\
Microcrystalline cellulose & $\mathrm{ND}$ & $\mathrm{ND}$ & $\mathrm{ND}$ \\
\hline$*$ not detected & & & \\
\hline
\end{tabular}

*, not detected.

242 Kinetic parameters

243 Using the colloid chitin as the substrate, the kinetic constants of the three chitinases

244 were determined and shown in Table 2. P1724 had the lowest $K_{m}$ value, followed by

$245 \mathrm{P} 1724 \mathrm{nGH} 18$, and then P1724cGH18; $K_{m}$ values of P1724 and P1724nGH18 were close

246 and lower than $1 \mathrm{mg} / \mathrm{mL}$, but the value of P1724cGH18 was much higher and about 2.1

$247 \mathrm{mg} / \mathrm{mL}$. Generally, an enzyme with a low $K_{m}$ has a high affinity for its substrate;

248 therefore, P1724 and P1724nGH18 had the higher affinity for the colloid chitin than

249 P1724cGH18. P1724 also had the highest $k_{c a t}$ and $K_{m} / k_{\text {cat }}$ values (Table 2), and so the

250 catalytic efficiency; $K_{m} / k_{\text {cat }}$ values of P1724 was obviously higher than the sum values

251 of nGH18 and cGH18 working individual, suggested that the individual domains of

252 P1724 working cooperatively to achieve higher hydrolytic efficiency. 
Table 2. Kinetic parameters of three recombinant chitinases toward colloid chitin.

\begin{tabular}{llll}
\hline Parameters & P1724 & P1724nGH18 & P1724cGH18 \\
\hline$K_{m}(\mathrm{mg} / \mathrm{mL})$ & $0.6 \pm 0.1$ & $0.8 \pm 0.1$ & $2.1 \pm 0.3$ \\
$V_{\max }$ & $3.2 \pm 0.1$ & $1.8 \pm 0.12$ & $1.7 \pm 0.1$ \\
$k_{\text {cat }}\left(\mathrm{s}^{-1}\right)$ & 5.4 & 2.0 & 1.5 \\
$k_{\text {cat }} / K_{m}(\mathrm{~mL} / \mathrm{s} \cdot \mathrm{mg})$ & 9.0 & 2.5 & 0.7 \\
\hline
\end{tabular}

255

256

257

\section{Hydrolysis pattern of the P1724 and its individual chitinolytic domains}

The hydrolysates of the recombinant chitinases towards colloid chitin were analyzed by the thin layer chromatography (TLC) method. After the reaction mixtures were incubated at $40 \mathrm{C}$ for $1 \mathrm{~h}, 1 \mathrm{ul}$ of each reaction mixture or $1 \mathrm{ul}$ of each 15 -time concentrated reaction mixture was loaded on the TLC plates. Without being concentrated, only N, $\mathrm{N}^{\prime}$-diacetylchitobiose $(\mathrm{GlcNAc})_{2}$ was detected on the TLC plate from all three chitinases (Fig. 7a). After being concentered, (GlcNAc) $)_{2}$ was the densest product on the plate, and GlcNAc and other oligomers (GlcNAc) $)_{>2}$ also showed up on the plate (Fig. 7b).

\section{Discussion}

In this study, we cloned, expressed, and characterized a chitinase (P1724) from the metagenome of a chitin-enriched community. Different from most of the microbial chitinases that contain only one catalytic domain, P1724 contains two. So far, four microbial chitinases with dual GH18 domain had been characterized, and they are Tk-ChiA from Archaeon T. kodakaraensis KOD1 [18], Chitinase B from S. degradans 2-40 [19], VChti-1 from Chlorella Virus [17], and ChiW from Paenibacillus sp. strain FPU-7[20, 25]. These chitinases were all obtained from the purified microorganisms, and so P1724 is the first microbial chitinase with dual catalytic domains discovered by the metagenomic approach. 
275 Chitinase P1724 was obtained from a community incubated under a cold and anoxic

276 condition. The amino acid sequence of P1724, its nGH18 or cGH18 showed the highest

277 identities with the hypothetical proteins or chitinases from anaerobes, such as

278 Clostridium sp. Marseille-P299, Lachnoclostridium spp., Anaerocolumna spp.,

279 Ruminiclostridium (Fig. 2); therefore, P1724 should belong to an anaerobe as well. So

280 far, only few studies focused on chitin degradation in cold-area wetlands under anoxic

281 conditions although anaerobic fermentation of chitin could be one of the important

282 processes of nitrogen cycling in such environments [22, 26, 27]. Using the

283 next-generation metagenomic method, we found this novel chitinases P1724 and

284 avoided culturing the cold-favoring chitinolytic anaerobes, such as Paludicola

psychrotolerans, which were normally hard to handle and very slow-growing [28]. Once

again, our study supports that the metagenomic method is a powerful tool to discover

new enzymes from extreme environments [29, 30].

Chitinase P1724 showed cold-adapted capacity. So far, most of the chitinases that had

been characterized exhibited the highest activity $\geq 50{ }^{\circ} \mathrm{C}$, and a few chitinases had been

reported to be psychrotolerant or psychrophilic with optimal working temperature $\leq$

$30{ }^{\circ} \mathrm{C}[31,32]$. Although $\mathrm{P} 1724$ showed the highest hydrolytic activities at $40{ }^{\circ} \mathrm{C}$, which

is higher than most of the psychrotolerant chitinases reported, P1724 is still

cold-adapted since it could hydrolyze colloid and powdery chitin at the low

temperatures, such as $4{ }^{\circ} \mathrm{C}$ (Table 1). So far, cold-adapted or psychrophilic chitinases

have shown the advantages in some applications where the low temperatures were demanded or could be not avoid, such as the preparation of chitooligosaccharides used for food or drugs, and the biocontrol of plant pathogens in the field and spoilage microorganisms in refrigerated food [31]. Therefore, P1724 could have the potential to

299 be applied in such industries. 
300 Two GH18 domains of P1724 are distinctive to each other in sequences and have unique hydrolytic modes. Based on the amino acid sequence similarity, GH18 chitinases could be classified into three subfamilies A, B, and C [33]. The main structural difference among these subfamilies is that a chitinases insertion domain (CID, a small $\alpha+\beta$ domain) inserts into the TIM barrel catalytic domain in the subfamily A, while subfamilies B and C have no such domain [33]. nGH18 of P1724 contains a CID, while cGH18 does not (Fig. 1); therefore, nGH18 should belong to subfamily A, while cGH18 should belong to subfamily B since it has best sequence similarity with subfamily B -type Chitinase D from Bacillus circulans [23]. Generally subfamily A chitinases are believed to be processive exochitinases, while subfamily B chitinases are non-processive modular endochitinases containing a catalytic domain and one or more CBMs [34]. Although P1724cGH18 made in this study matches the subfamily B chitinase module (one catalytic domain and two CBMs), it showed both (relatively weaker) endochitinase and (stranger) exochitinase activities (Table 1). P1724nGH18 containing one subfamily A catalytic domain and two CBMs showed not only the exochitinase activity like other subfamily A chitinases [34], but also the endochitinase activity (Table 1). Certainly, P1724, which is made up of nGH18 and cGH18, also showed both endochitinase and exochitinase activities. Further studies on crystal structure of chitinase-substrate complexes may help to elucidate the unique hydrolytic modes of P1724 and its nGH18 and cGH18 domains. Chitinase that have two or three different catalytic modes among endochitinase, exochitinase and $\mathrm{N}$-acetylglucosaminidase is considered to have broad specificity [35]. Compared with the chitinases with single catalytic mode, chitinases with broad specificity have more advantages in lowering the cost in the extraction process and increasing the catalytic efficiencies of the enzymes [35]. Therefore, we believe P1724, P1724nGH18 and 
P1724cGH18 could have advantages in applications due to their broad specificity. P1724 shared more similar in biochemical features with its nGH18 domain than its cGH18 domain. In responding to the temperatures, unlike cGH18 domain (P1724cGH18) was still stable around $45^{\circ} \mathrm{C}, \mathrm{P} 1724$ and its $\mathrm{nGH} 18$ domain (P1724nGH18) lost most of the activities at $45^{\circ} \mathrm{C}$ or preincubated at $45^{\circ} \mathrm{C}$ significantly (Figure $4 \mathrm{a}, 4 \mathrm{~b})$. In responding to the $\mathrm{pHs}$, unlike cGH18 was stable through $\mathrm{pH} 3-10$, P1724 and nGH18 domain lost most of their activities at pH 3.0 and 4.0 (Figure 4d). In term of tolerances to the salt, $\mathrm{P} 1724$ and $\mathrm{nGH} 18$ lost $50 \%$ activities around $1.25 \mathrm{M}$ $\mathrm{NaCl}$, while cGH18 was more tolerant and lost $50 \%$ of its maximus activity at higher concentration of $\mathrm{NaCl}(\sim 1.75 \mathrm{M})$. In responds to metal irons, $\mathrm{Fe}^{3+}$ decreased the activities of P1724 and nGH18, but had a contrary effect on cGH18. In addition, P1724 and nGH18 domain had the similar the $K_{m}$ values, and so the similar affinities to the colloid chitin, while the $K_{m}$ values of cGH18 was much higher than theirs (Table 2). Therefore, we would conclude nGH18 domain contributed more than cGH18 did in the biochemical features of P1724.

P1724 showed synergy between its two GH18 domains in term of catalytic efficiency. P1724 had highest catalytic efficiency, and its $k_{c a t} / K_{m}$ value was significantly higher than the sum value of nGH18 and cGH18. Studies already discussed that the chitinases with two catalytic domains had the advantages over the ones with a single catalytic domain [15]. Among many chitinases with a single catalytic domain that had been studied for their kinetic parameter for colloid chitin [1, 36-38], chitinase A from Vibrio harveyi [39] and EcChi1 from Enterobacter cloacae subsp.cloacae [40] had a similar optimum temperature $\left(37-40^{\circ} \mathrm{C}\right)$ with P1724. Chitinase A had $K_{m}, k_{c a t}$ and $k_{c a t} / K_{m}$ values of $12 \pm 1.4 \mathrm{mg} / \mathrm{mL}, 0.10 \mathrm{~s}^{-1}$ and $83 \times 10^{-4} \mathrm{~mL} / \mathrm{s} \cdot \mathrm{mg}$ respectively, and EcChi1 had $K_{m}, k_{c a t}$, and $k_{c a t} / K_{m}$ values of $15.2 \mathrm{mg} / \mathrm{mL}, 0.16 \times 10^{2} \mathrm{~min}^{-1}$ and $0.011 \times 102 \mathrm{~mL} / \mathrm{s} \cdot \mathrm{mg}$ 
respectively. Compared with these two chitinases, P1724 including its individual catalytic domains indeed had higher affinities and catalytic efficiencies towards the colloid chitin since they showed lower $K_{m}$ and higher $k_{c a t}$, and $k_{c a t} / K_{m}$ values. Therefore P1724 might have a better application potential.

P1724 and its individual catalytic domains showed better hydrolytic activities towards amorphous form than solid form of the substrates. Other than colloid chitin and soluble diacetylchitobiosid, triacetylchitotriose, and also glycol chitin in the zymogram test, P1724 and its individual catalytic domains also showed hydrolytic activities towards 10\% powdery chitin, but not $1 \%$ powdery chitin, which suggested that they had lower affinity toward the crystalline form of chitin than the colloidal form. As for chitosan, P1724 and its individual catalytic domains could hydrolyze colloid chitosan, but not $1 \%$ or $10 \%$ powdery chitosan, further confirmed that P1724 and its individual catalytic domains had better hydrolytic activities towards amorphous form than solid form of substrates. This is most likely due to colloidal chitin or chitosan are more accessible for the active site of chitinases than their crystalline form [1]. A few other chitinases had been reported to have hydrolytic activities on chitosan, such as Chitinase Chi1 from Myceliophthora thermophila C1 [41], a chitinase from P. timonensis strain LK-DZ15 [37] and Chit42 from Trichoderma harzianum [42]. Previous studies reporting that the GH18chitinases were able to cleave the glycosidic linkage of not only GlcNAc-GlcNAc in chitin but also GlcNAc-GlcN present in chitosan [43], which would explain that P1724 and its individual GH18 domains could hydrolyze chitosan as well.

P1724 and its catalytic domains showed various sizes of hydrolytic products towards colloid chitin, and (GlcNAc) $)_{2}$ was the major product. As discussed previously, all three chitinases showed both chitobiosidase and endochitinase activities and no $\beta$-N-acetylglucosaminidase activity. Endochitinase activity of all three chitinases could 
produce wide range of oligomers $(\mathrm{GlcNAc})_{\geq 2}$, and chitobiosidase activity mainly produced $(\mathrm{GlcNAc})_{2}$. Endochitinase and chitobiosidase both produce $(\mathrm{GlcNAc})_{2}$, which should not be further hydrolyzed to GlcNAc without $\beta$-N-acetylglucosaminidase, therefore, $(\mathrm{GlcNAc})_{2}$ became the predominant products. In addition, oligomers $(\mathrm{GlcNAc})_{3}$ could be hydrolyzed further by chitobiosidase to $(\mathrm{GlcNAc})_{2}$ and GlcNAc, and so GlcNAc showed up as one of final products. Chitin oligosaccharides have attracted much attention in recent years because of their functions as antimicrobial, anti-tumor, hypoglycemic agents and plant elicitors [44]. P1724, P1724nGH18 and P1724cGH18 obtained in this study could be useful chitinase resources to produce chitin oligosaccharides from chitin biomass in a greener industrious process compared to the traditional processes using concentrated acids or alkalis [8].

\section{Conclusion}

In summary, we discovered, obtained and characterized a chitinase with dual GH18 catalytic domains from a wetland on the Qinghai-Tibetan plateau using the metagenomic and genetic engineering approaches. The results showed that the chitinase (P1724) is unique in the amino acid sequence and catalytic mode. One of catalytic domains in P1724 played a dominant role in the biochemical characteristics of P1724, while both domains worked synergistically and made P1724 having higher catalytic efficiency. P1724 and its individual domains have broad specificity and are cold-adapted, and so could have an application potential in the industries or environments requiring low temperatures.

\section{Methods}

\section{Microbial consortium enrichment}

A soil sample was collected from Haiyan wetland on the Qinghai-Tibetan Plateau, China $\left(101^{\circ} 69^{\prime} \mathrm{N}, 36^{\circ} .588^{\prime} \mathrm{E}, 2,986 \mathrm{~m}\right.$ above sea level) in July 2013 , and then was 
processed and incubated with chitin flakes as a sole carbon resource at $15{ }^{\circ} \mathrm{C}$ under

401

402

403

404

405

406

407 anaerobic condition. After subcultured repeatedly for two years, the microbiome was collected by centrifugation and used for next-generation metagenomic sequencing. For more detailed information on sample processing, please refer to our previous publication [22].

\section{Metagenomic sequencing and CAZyme annotation}

The total DNA was extracted, sonicated, and used to construct a paired-end library with an insert size of $\sim 450$ base pairs DNA. The Illumina HiSeq platform (paired-end, $2 \times 150$ bp) were used for sequencing. Abound 7.5 Gb data high-quality reads were generated and assembled using IDBA (http://i.cs.hku.hk/ alse/hkubrg/projects/idba_ud/).

Gene-coding sequences were predicted on the assembled contigs using MetaGeneMark [45]. Predicted proteins were used to do CAZyme annotation in dbCAN

(http://csbl.bmb.uga.edu/dbCAN/annotate.php). Gene P1724 was discovered and predicted to have two GH18 catalytic domains.

\section{Domain and sequences analyses}

The InterProScan was used to search and analyze conserved domains and signature sequences (http://www.ebi.ac.uk/interpro/search/sequence/). The database homology search of the nucleotide and amino acid sequences was performed at NCBI BLAST [46].

The ProtParam tool was used to calculated the physicochemical characteristics (http://web.expasy.org/protparam/) [24]. The signal peptide was analyzed at the Signal P 3.0 server (http://www.cbs.dtu.dk/services/SignaIP-3.0). Phylogenetic analysis and tree of amino acid sequences was carried out in the Interactive Tree of Life online tool (http://itol.embl.de/).

\section{Gene cloning}

P1724 has 2883 base-paired nucleic acids and encodes a protein with 961 amino acids. 
425 In case the first 10 amino acids may be the secretion signal and have an effect on the 426 solubility of recombinant protein, they were eliminated, and then a 2853-bp fragment

427 (nt 31 to 2880) of $P 1724$ was amplified by PCR from the total DNA. The PCR primers were P1724F_KpnI (5'-CCGGGGTACCCACGTATCGGCAAATGAGAACT-3') and P1724R_BamHI (5'-GCGCGGATCCCTATTCAAACTCAGCAAAAC-3'). In addition, the fragment (nt 31 to 1884) of P1724 containing N-terminal GH18 catalytic domain and the CMBs was amplified using the primer pair of P1724F_KpnI and P1724(1884)R_BamHI (5'-GCGCGGATCCCTATATTACACCCCCTATTTTG-3’), and the fragment (nt 1372 to 2880) containing C-terminal GH18 catalytic domain and the CMBs was amplified using the primer pair of P1724(1372)F_KpnI (5'-CCGGGGTACCATACCGACTCCTACACCAA T-3') and P1724R_BamHI. All obtained PCR fragments were cloned into the vector pCold I (Takara Biomedical Technology (Beijing) Co., Ltd, China). The resultant constructs were transformed into $E$. coli BL21 (DE3) cells for the overproduction of the recombinant proteins.

\section{Gene expression and protein purification}

Overnight cultures of E. coli strain BL21 harboring the recombinant plasmids were used to inoculate LB broth (10 g/L peptone, $5 \mathrm{~g} / \mathrm{L}$ yeast extract, and $5 \mathrm{~g} / \mathrm{L}$ sodium chloride, pH 7.0) containing $100 \mu \mathrm{g} / \mathrm{mL}$ ampicillin. The cultures were incubated at $37{ }^{\circ} \mathrm{C}$ and 200 rpm until an optical density of $0.4-0.5$. The cultures were then quickly refrigerated at $15{ }^{\circ} \mathrm{C}$ and left to stand for 30 minutes. IPTG was added into the culture at the final concentration of $1.0 \mathrm{mM}$, and then the cultures were continued to shake at $15{ }^{\circ} \mathrm{C}$ for 24 hours. The recombinant proteins (chitinases) were extracted using Ni-NTA resin (QIAGEN China (Shanghai) Co., Ltd.) as follows: cells were harvested by centrifugation at 5,000 $\mathrm{x}$ g for $10 \mathrm{~min}$ at $4^{\circ} \mathrm{C}$ and then resuspended in the non-denaturalizing lysis buffer with lysozyme $(1 \mathrm{mg} / \mathrm{mL})$. The cell suspensions were left 
on ice for $30 \mathrm{~min}$ and then sonicated for 1 second with 1 second interval for $20 \min$ (200

W). After sonification, the cell suspensions were centrifuged $\left(10,000 \mathrm{~g}, 30 \mathrm{~min}\right.$, at $\left.4^{\circ} \mathrm{C}\right)$

to remove the insoluble cell debris. The supernatants were immediately applied to the

Ni-NTA agarose affinity column and the chromatography was carried out gravitationally at $4{ }^{\circ} \mathrm{C}$. The columns were washed with the wash buffer $(20 \mathrm{mM}$ Tris$\mathrm{HCl}$ buffer, $\mathrm{pH} 8.0$ and $150 \mathrm{mM} \mathrm{NaCl}$ ) containing $20 \mathrm{mM}$ imidazole. Ni-NTA bound proteins were eluted with $250 \mathrm{mM}$ imidazole in the same buffer. To remove imidazole, the eluted fractions were then dialyzed using the cellulose membrane tubes (Solarbio

Science \& Technology, Co., Ltd, Beijing, China). The purified proteins were stored at $-80{ }^{\circ} \mathrm{C}$ until used.

\section{Determination of protein quantification, molecular weight and zymogram}

The concentrations of recombinant proteins were measured by BCA protein assay kit (Beyotime Biotechnology, Jiangsu, China). The molecular weights of the recombinant chitinases were determined using sodium dodecyl sulfate-polyacrylamide gel electrophoresis (SDS-PAGE) method. The protein size was estimated using standard protein markers (Takara Biomedical Technology (Beijing) Co., Ltd, China). After separating the samples, the gel was stained with Coomassie Blue Fast Staining Solution (Beyotime Biotechnology, Jiangsu, China). To detect chitinase activity, the zymogram method was used as indicated by Lee et al.[8]. Briefly, the protein samples were loaded into two native gels, one with and one without $0.1 \%$ glycol chitin. After electrophoresis, the gel without glycol chitin were stained by Coomassie Blue Fast Staining Solution, while the gel with $0.1 \%$ glycol chitin was incubated in refolding buffer [50 mM citrate buffer (pH 6.0), $1 \%$ Triton $\mathrm{X}-100]$ at $40{ }^{\circ} \mathrm{C}$ for $10 \mathrm{~min}$. Then, the gel was stained with $0.01 \%$ calcofluor white $\mathrm{M} 2 \mathrm{R}$ in $50 \mathrm{mM}$ citrate buffer ( $\mathrm{pH}$ 5.0), rinsed several times with distilled water and visualized on a UV transilluminator. 
476 Chitinase activities were determined by the dinitrosalicylic acid (DNS) method of Miller [47] using colloid chitin (from crab shell flakes, Biotechnology (Shanghai) Co., Ltd., China) as the substrate. Colloid chitin was made by the procedure of Li at el[48].

The standard enzyme reaction mixture was as follows: 5-10 $\mu \mathrm{L}$ purified enzyme solution, $90 \mu \mathrm{L} \mathrm{1 \%}$ colloidal chitin, $100 \mu \mathrm{L} 100 \mathrm{mM}$ citrate buffer (pH 6.0). The standard assay condition was the reaction mixtures were incubated at $40{ }^{\circ} \mathrm{C}$ for $1 \mathrm{~h}$. One unit of activity was defined as the amount of enzyme catalyzing the production of 1 $\mu$ mol of $\mathrm{N}, \mathrm{N}^{\prime}$-diacetylchitobiose $(\mathrm{GlcNAc})_{2}$ per min. 
samples in the standard reaction mixture at the temperatures of $4-60{ }^{\circ} \mathrm{C}$. To determine the thermal stability of the chitinases, enzyme samples in $50 \mathrm{mM}$ citrate buffer (pH 6.0) was incubated at the temperatures of 4 to $60{ }^{\circ} \mathrm{C}$ for $1 \mathrm{hr}$, then the remaining enzyme activities were measured in the standard enzyme reaction mixture and assay condition.

The effect of salt on the chitinases activity was measured in the presence of $0,0.5,1,1.5$,

2, 2.5 and $3 \mathrm{M} \mathrm{NaCl}$; the effects of metal ions and reducing agents on the chitinases activity were assayed in the presence of 1 and $5 \mathrm{mM}$ of each ions, EDTA and DTT; these irons included $\mathrm{Ba}^{2+}, \mathrm{Ca}^{2+}, \mathrm{Co}^{2+}, \mathrm{Cu}^{2+}, \mathrm{Fe}^{3+}, \mathrm{K}^{+}, \mathrm{Li}^{+}, \mathrm{Mg}^{2+}, \mathrm{Mn}^{2+}$ and $\mathrm{Zn}^{2+}$; each of mixture, which then was tested in standard assay condition.

\section{Substrate specificities and kinetic parameters of the recombinant chitinases}

Substrate specificities of the purified chitinases were assayed at $40{ }^{\circ} \mathrm{C}$ and $4{ }^{\circ} \mathrm{C}$ in 50 $\mathrm{mM}$ citrate buffer ( $\mathrm{pH}$ 6.0) using various substrates. The tested substrates included $1 \%$ (w/v) for colloidal chitin, chitosan and carboxymethyl cellulose (CMC, Shanghai Macklin Biochemical Co., Ltd.(China), $1 \%$ and $10 \%$ for chitin powder from shrimp shells (Sigma-Aldrich Corporation, USA), and 10\% chitosan powder and crystalline cellulose (Biotechnology (Shanghai) Co., Ltd., China).

Kinetic parameters of the recombinant chitinases for colloidal chitin were determined. The recombinant chitinases were mixed with various concentrations of colloid chitin $(0.25-6 \mathrm{mg} / \mathrm{mL})$ in $50 \mathrm{mM}$ citrate buffer $(\mathrm{pH} 6.0)$ and incubated at $40{ }^{\circ} \mathrm{C}$ for $10 \mathrm{~min}$. The $K_{m}$ and $V_{\max }$ values were then calculated from kinetic data using the Origin 2020 software.

TLC analysis of colloidal chitin hydrolysates produced by the recombinant 
then stopped by boiling for $10 \mathrm{~min}$. After centrifugation, the supernatants of mixtures were spotted onto an HSGF254 silica gel plate (Yantai Jiangyou silica gel Development Co., Ltd, China), or were concentrated about 15 times by a vacuum centrifuge and then spotted on the plate. TLC plates were developed with a solvent system containing isopropyl alcohol, water, and 25\% ammonia solution [20:5:1 (v:v:v)], prayed by aniline-diphenylamine reagent (4 $\mathrm{mL}$ of aniline, $4 \mathrm{~g}$ of diphenylamine, $200 \mathrm{~mL}$ of acetone, and $30 \mathrm{~mL}$ of $85 \%$ phosphoric acid)[8], and then baked at $150{ }^{\circ} \mathrm{C}$ for $5-10 \mathrm{~min}$. The hydrolysates were estimated using the chitooligosaccharides standard, a product of Tokyo Chemical Industry Co., Ltd., Japan.

\section{Additional file}

535 One additional file containing the nucleic acid and amino acid sequences of P1724 was provided.

\section{Ethics approval and consent to participate}

Not applicable.

\section{Consent for publication}

$540 \quad$ Not applicable.

\section{$541 \quad$ Availability of data and materials}

542 The datasets supporting the conclusions of this article are included within the article and 543 its additional files.

\section{Competing interests}

545 The authors declare that they have no competing interests

\section{$546 \quad$ Funding}

547 This work was supported by the National Natural Science Foundation of China 548 (41877042), Interdisciplinary Team Project from West Light Foundation of the Chinese 549 Academy of Sciences (2019XBZG_JCTD_ZDSYS_001), the funding of the Key 
Sciences.

\section{Authors' contributions}

YD designed and carried out most of the experiments and drafted the manuscript; FY,

XL, and HW did and assisted part of the experiments, ZY designed experiment, and revised and proofed the manuscript. All authors read and approved the final manuscript.

\section{Acknowledgements}

Not applicable.

\section{Reference}

1. Oyeleye A, Normi YM. Chitinase: diversity, limitations, and trends in engineering for suitable applications. Biosci Rep. 2018;38(4):BSR2018032300.

2. Robinson PK. Enzymes: principles and biotechnological applications. Essays Biochem. 2015;59:1-41.

3. Swiontek Brzezinska M, Jankiewicz U, Burkowska A, Walczak M. Chitinolytic Microorganisms and Their Possible Application in Environmental Protection. Curr Microbiol. 2014;68(1):71-81.

4. Islam R, Datta B. Diversity of chitinases and their industrial potential. Int J Appl Res. 2015;1:55-60.

5. Yan Q, Fong SS. Bacterial chitinase: nature and perspectives for sustainable bioproduction. Bioresour Bioprocess. 2015;2(1):31.

6. Sun X, Li Y, Tian Z, Qian Y, Zhang H, Wang L. A novel thermostable chitinolytic machinery of Streptomyces sp. F-3 consisting of chitinases with different action modes. Biotechnol Biofuels. 2019;12(1):136.

7. Zhang A, He Y, Wei G, Zhou J, Dong W, Chen K, et al. Molecular characterization of a novel chitinase CmChi1 from Chitinolyticbacter meiyuanensis SYBC-H1 and its use in N-acetyl-d-glucosamine production. Biotechnol Biofuels. 2018;11(1):179.

8. Lee H-J, Lee Y-S, Choi Y-L. Cloning, purification, and characterization of an organic solvent-tolerant chitinase, MtCh509, from Microbulbifer thermotolerans DAU221. Biotechnol Biofuels. 2018;11(1).

9. Fu X, Yan Q, Yang S, Yang X, Guo Y, Jiang Z. An acidic, thermostable exochitinase with $\beta$-N-acetylglucosaminidase activity from Paenibacillus barengoltzii converting chitin to $\mathrm{N}$-acetyl glucosamine. Biotechnol Biofuels. 2014;7(1):174.

10. Vester JK, Glaring MA, Stougaard P. Improved cultivation and metagenomics as new tools for bioprospecting in cold environments. Extremophiles. 2015;19(1):17-29.

11. Sjöling S, Stafford W, Cowan D. Soil Metagenomics: Exploring and exploiting the microbial gene pool. In: van Elsas JD, Jansson JK, Trevors JT, editors. Modern Soil Microbiology. Boca Raton: CRC Press, Taylor \& Francis; 2006. p. 409-34.

12. Berini F, Casciello C, Marcone GL, Marinelli F. Metagenomics: novel enzymes from non-culturable microbes. FEMS Microbiol Lett. 2017;364(21).

13. Hjort K, Presti I, Elväng A, Marinelli F, Sjöling S. Bacterial chitinase with phytopathogen control capacity from suppressive soil revealed by functional metagenomics. Appl Microbiol Biotechnol. 2014;98(6):2819-28.

14. Cretoiu MS, Berini F, Kielak AM, Marinelli F, van Elsas JD. A novel salt-tolerant chitobiosidase discovered by genetic screening of a metagenomic library derived from chitin-amended agricultural soil. Appl Microbiol Biotechnol. 2015;99(19):8199-215.

15. Liu Y, Yan Q, Yang S, Jiang Z. Novel Protease-Resistant Exochitinase (Echi47) from Pig Fecal Environment DNA with Application Potentials in the Food and Feed Industries. J Agric Food Chem. 2015;63(27):6262-70. 16. Thimoteo SS, Glogauer A, Faoro H, de Souza EM, Huergo LF, Moerschbacher BM, et al. A broad 
pH range and processive chitinase from a metagenome library. Braz J Med Biol Res. 2017;50(1):e5658-e. chitinase. J Biosci Bioeng. 2000;89(3):252-7.

18. Tanaka T, Fukui T, Imanaka T. Different cleavage specificities of the dual catalytic domains in chitinase from the hyperthermophilic archaeon Thermococcus kodakaraensis KOD1. J Biol Chem. 2001;276(38):35629-35.

19. Howard MB, Ekborg NA, Taylor LE, Weiner RM, Hutcheson SW. Chitinase B of "Microbulbifer degradans" 2-40 contains two catalytic domains with different chitinolytic activities. J Bacteriol. 2004;186(5):1297-303.

20. Itoh T, Hibi T, Fujii Y, Sugimoto I, Fujiwara A, Suzuki F, et al. Cooperative degradation of chitin by extracellular and cell surface-expressed chitinases from Paenibacillus sp. strain FPU-7. Appl Environ Microbiol. 2013;79(23):7482-90.

21. Ekborg NA, Gonzalez JM, Howard MB, Taylor LE, Hutcheson SW, Weiner RM. Saccharophagus degradans gen. nov., sp. nov., a versatile marine degrader of complex polysaccharides. Int J Syst Evol Microbiol. 2005;55(4):1545-9.

22. Dai Y, Yan Z, Jia L, Zhang S, Gao L, Wei X, et al. The composition, localization and function of low-temperature-adapted microbial communities involved in methanogenic degradations of cellulose and chitin from Qinghai-Tibetan Plateau wetland soils. J Appl Microbiol. 2016;121(1):163-76.

23. Fukamizo T. Chitinolytic Enzymes: Catalysis, Substrate Binding, and their Application. Curr Protein Peptide Sci. 2000;1(1):105-24.

24. Gasteiger E, Hoogland C, Gattiker A, Duvaud Se, Wilkins MR, Appel RD, et al. Protein Identification and Analysis Tools on the ExPASy Server. In: Walker JM, editor. The Proteomics Protocols Handbook. Totowa, NJ: Humana Press; 2005. p. 571-607.

25. Itoh T, Sugimoto I, Hibi T, Suzuki F, Matsuo K, Fujii Y, et al. Overexpression, purification, and characterization of Paenibacillus cell surface-expressed chitinase ChiW with two catalytic domains. Biosci Biotechnol Biochem. 2014;78(4):624-34.

26. Ivanova AA, Wegner C-E, Kim Y, Liesack W, Dedysh SN. Identification of microbial populations driving biopolymer degradation in acidic peatlands by metatranscriptomic analysis. Mol Ecol. 2016;25(19):4818-35.

27. Kang H, Freeman C, Soon park S, Chun J. N-Acetylglucosaminidase activities in wetlands: a global survey. Hydrobiologia. 2005;532(1):103-10.

28. Li Y, Zhang LL, Liu L, Tian YQ, Liu XF, Li WJ, et al. Paludicola psychrotolerans gen. nov., sp. nov., a novel psychrotolerant chitinolytic anaerobe of the family Ruminococcaceae. Int J Syst Evol Microbiol. 2017;67(10):4100-3.

29. Berini F, Casciello C, Marcone G, Marinelli F. Metagenomics: novel enzymes from nonculturable microbes. FEMS Microbiol Lett. 2017;364.

30. Siddiqui KS. Some like it hot, some like it cold: Temperature dependent biotechnological applications and improvements in extremophilic enzymes. Biotechnol Adv. 2015;33(8):1912-22. 31. Wang X, Chi N, Bai F, Du Y, Zhao Y, Yin H. Characterization of a cold-adapted and salt-tolerant exo-chitinase (ChiC) from Pseudoalteromonas sp. DL-6. Extremophiles. 2016;20(2):167-76.

32. Wang X, Zhao Y, Tan H, Chi N, Zhang Q, Du Y, et al. Characterisation of a chitinase from Pseudoalteromonas sp. DL-6, a marine psychrophilic bacterium. Int J Biol Macromol. 2014;70:455-62. 33. Li H, Greene LH. Sequence and structural analysis of the chitinase insertion domain reveals two conserved motifs involved in chitin-binding. PLoS One. 2010;5(1):e8654-e.

34. Wang Y-J, Jiang W-X, Zhang Y-S, Cao H-Y, Zhang Y, Chen X-L, et al. Structural Insight Into Chitin Degradation and Thermostability of a Novel Endochitinase From the Glycoside Hydrolase Family 18. Front Microbiol. 2019;10:2457.

35. Zhou J, Chen J, Xu N, Zhang A, Chen K, Xin F, et al. The broad-specificity chitinases: their origin, characterization, and potential application. Appl Microbiol Biotechnol. 2019;103(8):3289-95. 36. Laribi-Habchi H, Bouanane-Darenfed A, Drouiche N, Pauss A, Mameri N. Purification, characterization, and molecular cloning of an extracellular chitinase from Bacillus licheniformis stain LHH100 isolated from wastewater samples in Algeria. Int J Biol Macromol. 2015;72:1117-28. 37. Yahiaoui M, Laribi-Habchi H, Bouacem K, Asmani K-L, Mechri S, Harir M, et al. Purification and biochemical characterization of a new organic solvent-tolerant chitinase from Paenibacillus timonensis strain LK-DZ15 isolated from the Djurdjura Mountains in Kabylia, Algeria. Carbohydr Res. 2019;483:107747.

38. Karthik N, Binod P, Pandey A. Purification and characterisation of an acidic and antifungal chitinase produced by a Streptomyces sp. Bioresour Technol. 2015;188:195-201.

39. Suginta W, Pantoom S, Prinz H. Substrate binding modes and anomer selectivity of chitinase A from Vibrio harveyi. J Chem Biol. 2009;2(4):191-202. 
40. Mallakuntla MK, Vaikuntapu PR, Bhuvanachandra B, Das SN, Podile AR. Transglycosylation by a chitinase from Enterobacter cloacae subsp. cloacae generates longer chitin oligosaccharides. Sci Rep. 2017;7(1):5113-. 41. Krolicka M, Hinz SWA, Koetsier MJ, Joosten R, Eggink G, van den Broek LAM, et al. Chitinase Chi1 from Myceliophthora thermophila C1, a Thermostable Enzyme for Chitin and Chitosan Depolymerization. J Agric Food Chem. 2018;66(7):1658-69.

42. Kidibule PE, Santos-Moriano P, Jiménez-Ortega E, Ramírez-Escudero M, Limón MC, Remacha M, et al. Use of chitin and chitosan to produce new chitooligosaccharides by chitinase Chit42: enzymatic activity and structural basis of protein specificity. Microb cell fact. 2018;17(1):47.

666 43. Ohtakara A, Matsunaga H, Mitsutomi M. Action Pattern of Streptomyces griseus Chitinase on 667 N-acetylated chitosan. Agric Biol Chem. 1990;54(12):3191-9.

668 44. Qin Z, Zhao L. The History of Chito/Chitin Oligosaccharides and Its Monomer. In: Zhao L, editor. Oligosaccharides of Chitin and Chitosan: Bio-manufacture and Applications. Singapore: Springer 45. Zhu W, Lomsadze A, Borodovsky M. Ab initio gene identification in metagenomic sequences. Nucleic Acids Res. 2010;38(12):e132-e. 46. NCBI Resource Coordinators. Database resources of the National Center for Biotechnology Information. Nucleic Acids Res. 2018;46(D1):D8-d13.

47. Miller GL. Use of Dinitrosalicylic Acid Reagent for Determination of Reducing Sugar. Anal Chem. 1959;31(3):426-8.

48. Li Y, Zhang L-L, Liu L, Tian Y-Q, Liu X-F, Li W-J, et al. Paludicola psychrotolerans gen. nov., sp. nov., a novel psychrotolerant chitinolytic anaerobe of the family Ruminococcaceae. Int J Syst Evol

680 
682

683

684

685

686

687

688

689

690

691

692

693

694

695

696

697

698

699

700

701

Fig. 1. Domain structures of P1724 and truncated portions of P1724 created for this study.

Fig. 2. Phylogenetic tree analysis of two GH18 domains of P1724.

Tree scale: 0.1 substitutions per nucleotide position.

Fig. 3. SDS-PAGE, Native PAGE, and zymogram analysis of the purified recombinant chitinases.

a. SDS-PAGE stained by Coomassie blue. b. Native PAGE stained by Coomassie blue. c. Native PAGE with $0.1 \%$ glycol chitin stained by calcofluor white M2R (zymogram). M, protein molecular mass marker, from top to bottom: 200, 116, 97.2, 66.4, and 44.3 KDa; Band i, P1724, band ii P1724nGH18 and band iii P1724cGH18.

Fig. 4. Effects of temperature and $\mathrm{pH}$ on three recombinant chitinases.

a. Optimum temperature. b. Temperature stability. c. Optimum pH. d. pH stability. Fig. 5. Effects of $\mathrm{NaCl}$ on three recombinant chitinases.

Fig. 6. Effects of metal irons and reducing agents on three recombinant chitinases.

Fig. 7. TLC analysis of colloidal chitin hydrolysates produced by three recombinant chitinases.

a. hydrolysis products without being concentrated. b. hydrolysis products concentrated 15 times. Lane Standard, G1-G6: GlcNAc - (GlcNAc)6. 
Figures

CMB 5/12

P1724

\begin{tabular}{|c|c|c|c|}
\hline GH18 & GH18 \\
CID & CMB 5/12
\end{tabular}

CMB 5/12

P1724nGH18

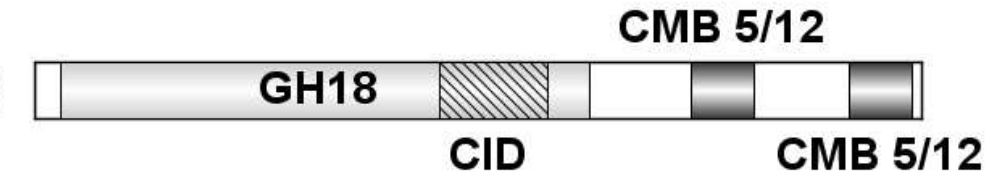

P1724cGH18

CMB 5/12

\begin{tabular}{|l|l|l|l|}
\hline$\square$ & & GH18 \\
\hline
\end{tabular}

CMB 5/12

Figure 1

Domain structures of P1724 and truncated portions of P1724 created for this study. 
Tree scale: 0.1

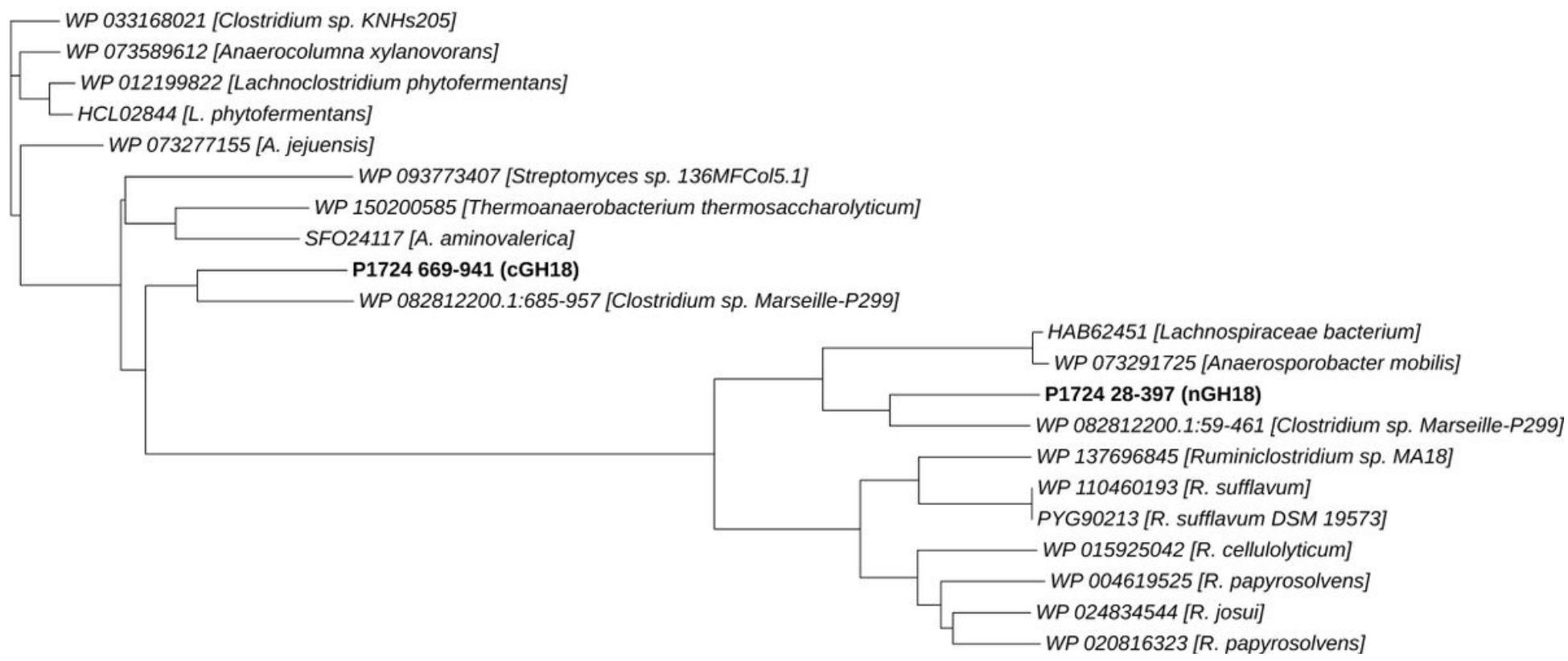

\section{Figure 2}

Phylogenetic tree analysis of two GH18 domains of P1724. Tree scale: 0.1 substitutions per nucleotide position. 


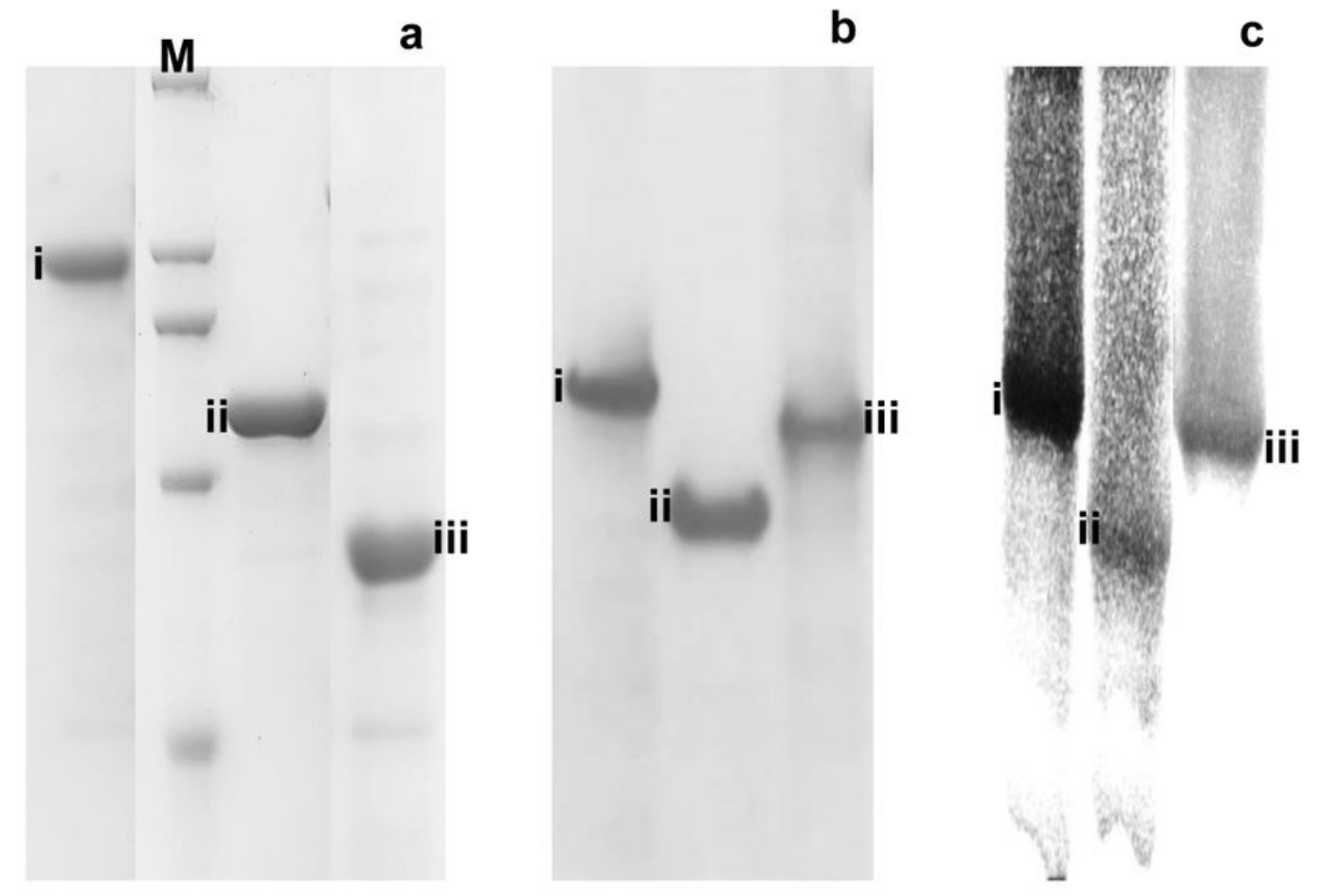

Figure 3

SDS $\triangle P A G E$, Native PAGE, and zymogram analysis of the purified recombinant chitinases. a. SDS-PAGE stained by Coomassie blue. b. Native PAGE stained by Coomassie blue. c. Native PAGE with $0.1 \%$ glycol chitin stained by calcofluor white M2R (zymogram). M, protein molecular mass marker, from top to bottom: $200,116,97.2,66.4$, and $44.3 \mathrm{KDa}$; Band i, P1724, band ii P1724nGH18 and band iii P1724cGH18. 

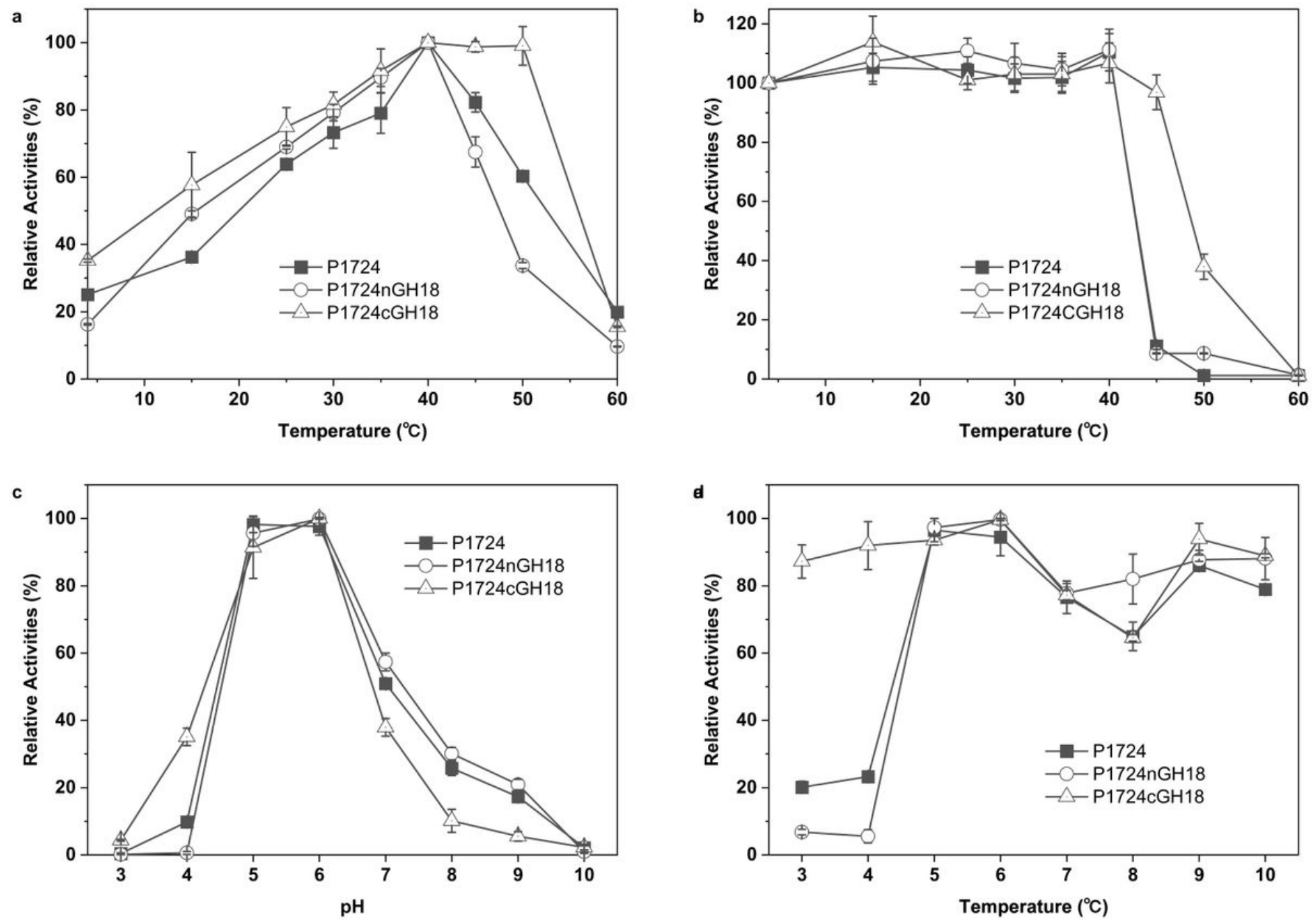

Figure 4

Effects of temperature and $\mathrm{pH}$ on three recombinant chitinases. a. Optimum temperature. b. Temperature stability. c. Optimum pH. d. pH stability. 


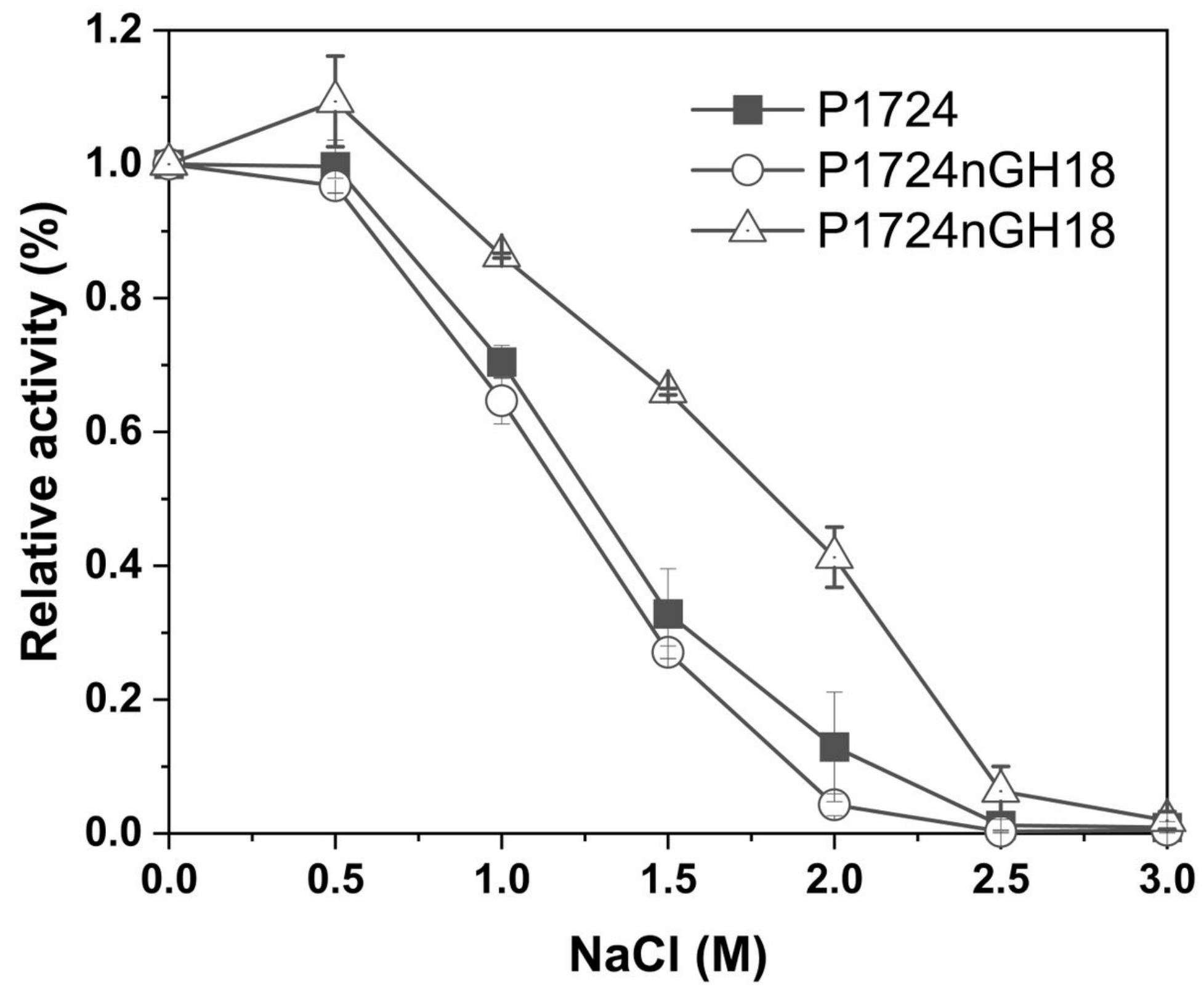

Figure 5

Effects of $\mathrm{NaCl}$ on three recombinant chitinases. 

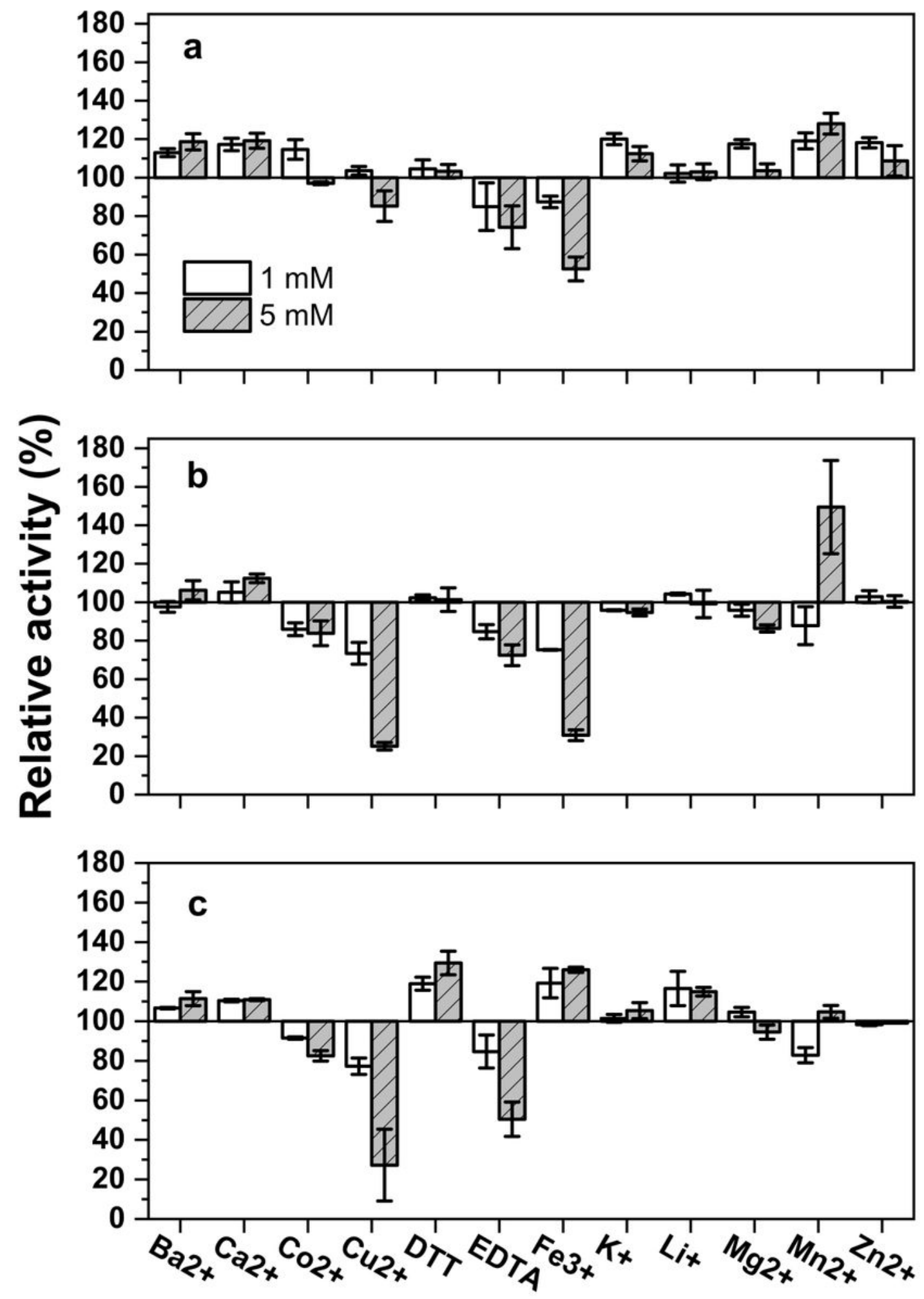

Figure 6

Effects of metal irons and reducing agents on three recombinant chitinases. 


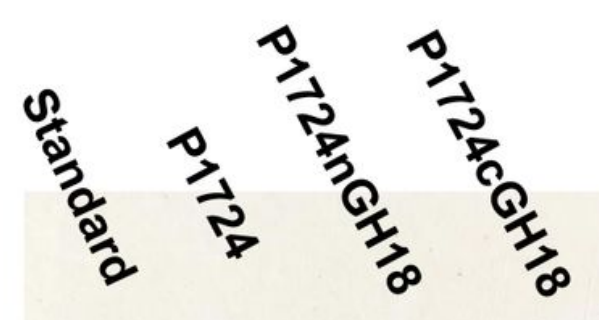

G1

G2

$\downarrow$

G3

G4

G5

G6

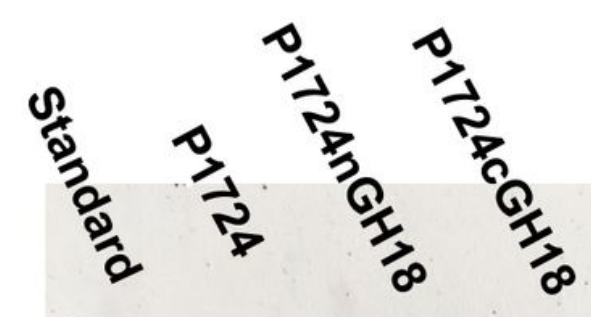

G1

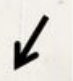

G2

G3

G4

G5

G6

a

b

Figure 7

TLC analysis of colloidal chitin hydrolysates produced by three recombinant chitinases. a. hydrolysis products without being concentrated. b. hydrolysis products concentrated 15 times. Lane Standard, G1G6: GlcNAc - (GlcNAc)6.

\section{Supplementary Files}

This is a list of supplementary files associated with this preprint. Click to download.

- CLY.Dai.pdf

- CLY.Dai.pdf

- Additinalfile.pdf

- Additinalfile.pdf 